\title{
Lasten yksilölliset piirteet, päiväkoti ja koti sekä perheen sosioekonominen asema muovaavat lasten paikallaanoloa
}

Helsingin sanomat kirjoitti vuonna 1963 eli melkein 60 vuotta sitten, että istumatyötä tekevän ihmisen päivittäinen liikkuminen saattoi helposti jäädä parin sadan askeleen mittaiseen kävelyyn. Hissillä ylös ja alas, bussilla tai raitiovaunulla työhön tai työstä kotiin, ilta kotona, usein televisiota katsellen tai muuten paikallaan pysyen. (1.) Kuulostaako tutulta? Tuskinpa kuitenkaan tämän artikkelin kirjoittanut toimittaja osasi aavistaa, miten fyysisesti passiivinen elämäntyyli on vallannut länsimaiset yhteiskunnat viime vuosikymmeninä. Verrattuna aiempiin sukupolviin, nykyihminen viettää entistä enemmän aikaa elinympäristöissä, mitkä rajoittavat liikkumista, mutta myös vaativat pitkäaikaista paikallaanoloa - kotona, autoissa, työpaikoilla, päiväkodeissa, kouluissa ja julkisilla paikoilla. Nyky-ympäristöt muovataan niin, että liikkumista ja lihastyötä vältetään. $(2,3$.) Esimerkiksi nykyään suurin osa ihmisistä länsimaissa tekee töitä istuen. Teknologian kehittyminen on tarkoittanut, että myös fyysisesti raskaat ja energiaa kuluttavat työt on nykyään usein automatisoitu koneiden tehtäväksi ja näin passivoittanut ihmisen työtä. On aiempaa todennäköisempää, että matkat päiväkotiin, kouluun tai töihin tehdään paikallaan ollen autolla tai istuen julkisissa liikennevälineissä kuin kävellen, juosten tai muuten lihastyötä tehden. Vielä 1970-luvulla lapsi alkoi katsoa televisiota keskimäärin neljän vuoden ikäisenä, nykyään jo noin viiden kuukauden ikäisenä. Vielä 1970-luvulla televisio oli todennäköisesti ainoa ruutu perheissä, kun nykyään ruutuja kotona on lukuisia. $(4,5,6,7$.) Tänä päivänä onkin mahdollista maata arki-ilta omalla sohvalla, tilata ruuat toimitettuna kotiovelle, vaihtaa kaukosäätimellä television kanavia sekä päivittää sosiaalisen median kautta kuulumiset kavereille, tuttaville ja ystäville ilman, että oikeastaan tarvitsee nousta sohvalta, ja vaivautua liikkumaan. Vaikka nämä arjen tavat ovatkin olleet erittäin hyödyllisiä sosiaalisten etäisyyksien aikana keväällä 2020, näillä kaikilla arjen toiminnoilla on pitkällä tähtäimellä kaksinkertainen vaikutus ihmisen käyttäytymiselle: ihmiset liikkuvat vähemmän ja ovat enemmän paikallaan. Ihminen on kuitenkin luotu liikkumaan, tekemään liikettä ja toteuttamaan ruumiillista työtä koko päivän ajan. Tämä oli myös olennaista ihmisen selviytymiselle aiemmin. (5.) Viime vuosikymmenien muutos fyysisesti vaativasta elämäntyylistä passiiviseen ovat olleet yllättäviä ja ne ovat tapahtuneet hyvin lyhyessä ajassa ihmiskunnan olemassa olon aikana. Tämä muutos näkyy kaikissa väestönryhmissä, myös päiväkoti-ikäisillä lapsilla. Tuoreen meta-analyysin johtopäätös on nimittäin, että jopa päiväkoti-ikäiset lapset ovat puolet heidän valveillaoloajastaan paikallaan. (8). Onkin ymmärrettävää, että kansainvälinen terveysjärjestö WHO on nostanut passiivisen elämäntyylin suureksi huolenaiheeksi ja yhdeksi keskeiseksi tekijäksi yleistyneessä lasten ylipainoisuudessa (9).

Paikallaanolo on käsitteenä uusi, vaikka ensimmäiset tutkimukset aiheesta on tehty jo 1950luvulla. Silti tutkimukset ovat enemmän olleet kiinnostuneita energian kulutuksen toisesta ääripäästä, reippaasta-rasittavasta liikkumisesta ja sitä selittävistä tekijöistä. Ensimmäinen kansainvälinen määritelmä paikallaanololle saatiin vasta vuonna 2011, ja tätä määritelmää tarkennettiin vuonna 2017. Paikallaanolo tarkoittaa valveilla tapahtuvaa käyttäytymistä, mikä kuluttaa enintään 1.5 metabolista ekvivalenttia energiaa, ja tapahtuu istuen, maaten tai loikoillen. (10.) Paikallaanolo ei ole sama kuin liikunnallisesti inaktiivinen. Istuminen on osa paikallaanoloa, mutta seisomista ei kuitenkin lasketa osaksi paikallaanoloa. (10.) Ruutuaika on yksi yleensä paikallaan tapahtuva käyttäytyminen, mutta paikallaanoloa on myös esimerkiksi kirjojen lukeminen tai leikkiminen paikallaan. Nämä esimerkit ku- 
vaavat miten paikallaanoloa on haasteellista mitata. Näinpä 2000-luvulla liikuntatutkimuksessa on yleistyneet objektiiviset mittarit, kuten liikemittarit, mitkä tarjoavat mahdollisuuden mitata entistä tarkemmin esimerkiksi kokonaispaikallaanoloaikaa päivässä. Liikemittarin datasta kaikki ihmisen käyttäytyminen valveillaoloaikana voidaan jakaa neljään intensiteettitasoon; paikallaanoloon, kevyeen, reippaaseen ja rasittavaan liikkumiseen. (11.) Yksinkertaistaen liikemittarin datasta saatava käyttäytyminen voidaan luokitella joko liikkeeksi tai paikallaanoloksi. Väitöskirjassani päiväkoti-ikäisten lasten paikallaanolo mitattiin objektiivisella mittarilla. Seuraten vuoden 2017 määritelmää (10), objektiivisesti mitattu paikallaanolo tarkoittaa minkä tahansa pituista aikaa vietettynä missä tahansa kontekstissa ollen paikallaan.

Objektiivisesti mitattu paikallaanolo antaakin siis mahdollisuuden tarkastella aikaa, mitä meillä kaikilla on saman verran käytettävissä joka päivä. Katse liikkumissuosituksissa onkin kääntynyt ymmärtämään, miten tämä $24 \mathrm{~h}$ jakautuu eri energian kulutustasoille. Monissa maissa suositukset kannustavat nykyään löytämään terveellisen arjen tasapainon liikkumisen, paikallaanolon ja unen välille (12). Paikallaanolon terveysvaikutuksia tarkastelleen meta-analyysin perusteella voidaankin yksinkertaistaa, että mitä enemmän valveillaoloaikana olet paikallasi, sitä vähemmän siis liikut millä tahansa teholla ja sitä suuremmaksi nousee ennenaikaisen kuolleisuuden riski. Jo kuitenkin liikkumalla yli tunnin päivässä vähintään reippaalla tasolla voidaan paikallaanolon riskejä lieventää tai jopa päästä kokonaan eroon. (13.) Silti kvantitatiivista raja-arvoa eli rajaa, jonka jälkeen paikallaanolo on harmillista tai jota ennen harmitonta, tuskin voinee määrittää (14). Yhä enemmissä määrin tutkimusnäyttö tukee myös, että pitkään kestänyt yhtäjaksoinen paikallaan oleminen on haitallista terveydelle, ja näin paikallaanolon säännöllinen tauottaminen on olennaista. Viime aikoina tutkijat ovatkin pohtineet, että onko vielä aika paikallaanolon suosituksille, koska paikallaanolosta käyttäytymisenä tiedetään yhä niin vähän eikä laadukasta tutkimusnäyttöä terveysvaikutuksista juurikaan ole. (15.) Kansanterveyden näkökulmasta voi olla kuitenkin tärkeää asettaa edes jokin suositus, jotta ilmiöön kiinnitetään huomiota laaja-alaisesti. Chaput ja hänen kanssa- kirjoittajat totesivatkin tuoreessa kommenttipuheenvuorossaan, että väliaikainen paikallaanolon suositus on parempi kuin ei suositusta ollenkaan (14).

Sanomalehdet ovat kuitenkin toitottanut pitkään, että paikallaanolo tappaa tai paikallaanolo on uusi tupakointi (16). Asiaa lähemmin tarkastelleessa australialaistutkimuksessa todettiin, että julkisessa puheessa eli pääsääntöisesti median kirjoittamissa artikkeleissa paikallaanolosta oli tehty yksilön vastuu ja yksilön tekemä valinta, mutta yksilöä ei syyllistetty liiallisesta paikallaanolosta. Puolestaan elinympäristön rooli paikallaanolossa mainittiin harvoin. (17.) Päinvastaisesti, väitöskirjani pääteoriakehys eli paikallaanolon sosioekologinen malli ehdottaa, että jokainen konteksti, jossa ihminen viettää aikaansa, vaikuttaa ja muovaa paikallaanolon mahdollisuuksia eri tavoin. Tähän muovautumiseen vaikuttaa kontekstin vallitsevat normit, asenteet, käsitykset ja uskomukset, mutta myös kontekstin fyysiset tekijät. (18.) Jos tarkastellaan väitöstilaisuuden salia, on normaalia ja normien mukaista olettaa, että jokainen muu on paikallaan paitsi väittelijä. Tätä valintaahan tukee myös fyysisen ympäristön oletukset eli saliin keskeisille paikoille sijoitetut tuolit. Tuskinpa kukaan osaisi kyseenalaistaa paikallaanoloa väitössalissa. Toisaalta koti ympäristönä mahdollistaa enemmän yksilöllisiä valintoja. On esimerkiksi yksilön valinta jääkö hän makaamaan sohvalle työpäivän jälkeen vai lähteekö ulos kävelylle. Kannustan kuitenkin pohtimaan uudestaan, että onko paikallaanolo yksilön vastuu, kun puhumme päiväkoti-ikäisistä lapsista. Päiväkoti-ikäiset lapset tarvitsevat vielä aikuista avuksi selvitäkseen monista arjen toiminnoista ja he vasta opettelevat erilaisia taitoja ja tottumuksia.

Paikallaanolon käsitettä voidaankin määritellä tapoina ja tottumuksina. Tavat muodostuvat vähitellen, kun yksilö oppii ympäristön signaalin ja toiminnon välisen yhteyden. Tavat aktivoituvat usein ympäristön ärsykkeestä ilman, että välttämättä tietoisesti päätetään sitoutua kyseiseen käyttäytymiseen. (19.) Tavat alkavat muovautua jo varhaislapsuudessa. Nyky-yhteiskunnassa keskeisessä roolissa päiväkoti-ikäisten lasten tapojen oppimisessa konteksteina ovat koti ja päiväkoti. Paikallaanolon sosioekologisen mallin mukaisesti voidaan olettaa, että koti ja päiväkoti eroavat konteksteina paikallaanolon suh- 
teen (18). Päiväkodin arjessa harjoitetut tavat ja tottumukset rakentuvat pitkälti ennalta suunnitelluista käytännöistä, joihin jokainen lapsi osallistuu oman taitotasonsa mukaisesti riippumatta heidän sosioekonomisista, kulttuurisista tai muista taustoistaan. Koti on puolestaan toisenlainen kasvuympäristö, jonka yksi keskeinen käytäntöjä, tapoja ja fyysistä ympäristöäkin muovaava tekijä on sosioekonominen asema. Sosioekonomisen aseman mukaisia terveyseroja esiintyy myös Suomessa; korkeamman sosioekonomisen aseman omaavat yksilöt elävät pidempään ja terveellisemmin kuin matalamman sosioekonomisen aseman omaavat yksilöt (20). Terveyseroihin vaikuttavat käyttäytymisen tavat opitaan usein varhaislapsuudessa, ja tällöin opitut tavat ennustavat aikuisiän terveyskäyttäytymistä, minkä takia varhaislapsuuden kotiympäristön tutkiminen on keskeistä. Kodin ja perheen sosioekonominen asema voi vaikuttaa suoraan tai epäsuoraan lasten terveyskäyttäytymiseen. Tutkimusten perusteella esimerkiksi vanhemmuuskäytännöt, sosiaalinen tuki ja roolimalli terveellisille elintavoille ovat heikompia matalan sosioekonomisen aseman perheissä, mitkä puolestaan vaikuttavat lasten heikompaan terveyskäyttäytymiseen (21). Käytännössä tämä väittämä tarkoittaa, että vaikka aika on demokraattisesti jaettu voimavara, korkeamman sosioekonomisen aseman perheet painottavat ajankäyttöä eri tavoin, yleensä terveellisemmin kuin matalamman sosioekonomisen aseman omaavat perheet. Ajankäytöllä on puolestaan merkitystä lasten tapojen oppimiselle. Väitöskirjani mukaan se, miten paljon tästä ajasta päiväkoti-ikäiset lapset käyttävät paikallaanoloon, on riippuvaista lapsen yksilöllisistä piirteistä, päiväkodista, kodista ja perheen sosioekonomisesta asemasta. Nostankin seuraavaksi esille muutamia keskeisiä tuloksia väitöskirjan pohjalta.

Väitöskirjani mukaan lapsen yksilölliset piirteet, kuten temperamentti tai sukupuoli, muovaavat lapsen paikallaanoloa. Jo Urie Bronfenbrenner (1979), sosioekologisen mallin isä, kirjoitti aikoinaan, että jokainen yksilö omine piirteineen reagoi eri tavoin samoihin ympäristön ärsykkeisiin, vaikka yksilöt ovat samassa kontekstissa (22). Vaikkei kaikkia lapsen yksilöllisiä piirteitä pystykään muovaamaan, jokaista kontekstia voidaan muovata huomioiden entistä tarkemmin lasten piirteet. Aiemmissa tutkimuksissa on huo- mattu, että päiväkodilla on kontekstina vähän merkitystä lasten liikkumiselle ja paikallaanololle, jos arjen käytännöissä lapsille sallitaan vapautta itse valita toimintoja ja leikkejä (23). Tällöin on kuitenkin tärkeämpää huomioida, että paikallaanoloa tauotetaan. Vapaus valita antaa nimittäin mahdollisuuden lapsille olla paikoillaan pitkiäkin aikoja. Varhaiskasvattajat, jotka osallistuivat DAGIS-tutkimuksen laadullisiin haastatteluihin, nostivat myös tämän seikan esille. Heidän mielestään päiväkodin arjessa oli lapsella mahdollisuus olla pitkiäkin aikoja paikallaan, jos tähän ei kiinnitetty huomiota. (24.) Väitöskirjani alleviivaa, että päiväkodin rakenteellisilla tekijöillä, kuten liikuntatuokioilla ja liikunnan teemaviikoilla, on merkitystä paikallaanolon vähentämisessä. Näistä hyötyvät varsinkin lapset, joille kertyisi enemmän paikallaanoloa päiväkodissa ilman näitä rakenteellisia tekijöitä. Samoin varhaiskasvattajan käytäntö tauottaa paikallaanoloa usein on tärkeä. Tulokset siis kannustavat lisäämään päiväkodin arjen rytmiin jo Helsingin sanomien vuonna 1963 kehottamaa taukovoimistelua. Nimittäin aiemmin mainitussa Helsingin sanomien artikkelissa ratkaisuksi paikallaanolon tauottamiseksi tarjottiin taukovoimistelua, jolla tarkoitettiin työpaikalla tai sen läheisyydessä yksi tai pari kertaa päivässä tapahtuvaa muutaman minuutin voimisteluhetkeä. (1.)

Väitöskirjani tulokset kannustavat pohtimaan myös ulkoilun merkitystä paikallaanolon tauottajana. Ajankäyttötutkimukset useassa länsimaassa ovat huomanneet, että nykylapset viettävät vähemmän aikaa ulkona kuin heidän omat vanhempansa omassa lapsuudessaan $(25,26)$. Vuoden 2011 perhebarometrissa selvitettiin tarkemmin suomalaisperheiden ulkoilua. Tämän mukaan pienten lasten perheissä käytettiin keskimäärin vähemmän aikaa lasten kanssa ulkoiluun kuin esimerkiksi lasten saattamiseen ja kuljettamiseen eri paikkoihin. (27.) Perhebarometrin ja muiden tutkimusten mukaan pienten lasten vanhemmat käyttäisivätkin enemmän aikaa liikkumiseen ja ulkoiluun, jos lisäaikaa olisi saatavilla, mutta kun kaikilla on kuitenkin käytettävissä vain 24 h vuorokaudessa $(27,28)$. Voikin kysyä, että mikä arjen rytmissä on muuttunut viime vuosikymmeninä niin paljon, että ulkoilulle ei jää aikaa. On todettu lisääntyneen ajan ruutujen ääressä vaikuttavan, mutta myös sen, että vanhemmat yhä enemmissä määrin ylisuojelevat 
lapsiaan ulkoisilta haitoilta kuten loukkaantumisilta. Näin ollen vanhemmat haluavat pitää lapsiaan sisällä, antaa heille ohjattuja toimintoja ja pitää heidät oman valvovan silmän alla. Ulkoilu koetaan myös arjen kiireessä liian aikaa vievänä, stressaavana ja energiaa kuluttavana, kun puolestaan sisällä paikallaanolo on helpompaa ja aikaa säästävää. $(28,29$.) Perhebarometrin mukaan kiirettä arjessa kokivat varsinkin ne vanhemmat, jotka käyttivät myös enemmän aikaa vapaa-ajalla tapahtuviin liikkumisiin paikasta toiseen (27). Onkin lohdullista väittää tämän väitöskirjan pohjalta, että lasten vähäisemmän paikallaanolon suhteen tärkeämpää ovatkin lähiympäristöt eli oma piha ja metsä.

Tässä väitöskirjassa havaittiin myös sosioekonomisia eroja perhekäytännöissä. Esimerkiksi matalamman sosioekonomisen aseman omaavat perheet vierailivat useammin omilla pihoillaan, ja tämä tiheys vähensi lasten paikallaanoloa. Tämä tulos voi kuulostaa vastakkaiselta kuin odotettiin. Tämä tutkimustulos voi kuitenkin heijastaa nykyisiä yhteiskunnallisia normeja, ja normit omaksutaan yleensä ensin korkeamman sosioekonomisen aseman omaavien yksilöiden keskuudessa. Aiemmin kuvatut yhteiskunnalliset muutokset ovat johtaneet siihen, että fyysisesti passiivinen elämäntyyli on vallitseva normi nykyään, ja se näkyy ajankäytössä (30). Tätä näkemystä tukee tuore laadullinen haastattelututkimus, johon osallistuneet vanhemmat toivat esille, että lapset olivat paikallaan, koska muutkin tekivät niin, ja tämä tapa opitaan mallioppimalla muilta tärkeiltä yksilöiltä (31). Onkin syytä pohtia, että tulisiko ulkoilun merkitystä lähiympäristössä korostaa entisestään ja nostaa ulkoilua arvostusta perheiden silmissä, jotta ulkoilusta tulisi tapa sisälläolon sijaan. Yksi keskeinen mallioppimisen ympäristö perheille voisi olla päiväkoti, jos lapsi siirtäisi opitut tavat luontoretkistä päiväkodista kotiin. Perhebarometrin mukaan suomalaiset perheet arvostavat yhdessäoloa, vaikka se tapahtuisikin kotona, eri huoneissa ja eri asioiden parissa (27). On kuitenkin roolimallin, tapojen muodostumisen, taitojen kehittymisen, sosiaalisten suhteiden ja paikallaanolon kannalta merkitystä sillä, miten perhe on yhdessä - liikkuen vai paikallaan, yhdessä vai erikseen, sisällä vai ulkona.

Okinawan saarella Japanissa elää onnellisia ja pitkäikäisiä ihmisiä. Heidän pitkäikäisyyden salaisuutena pidetään elämänasennetta, mikä ikigaina tunnetaan. Osana ikigaita todetaan, että on helppoa olla vähemmän paikallaan. Se vaatii vain jonkin verran panostuksia arjen tapoihin eli kävele päivittäin vähintään 20 minuuttia, käytä jalkoja hissien ja rullaportaitten sijaan, osallistu sosiaalisiin toimintoihin ja vapaa-ajan aktiviteetteihin sen sijaan, että katsot televisiota, leiki yhdessä lasten, eläinten tai kavereiden kanssa sekä tiedosta omat arjen rutiinisi ja tunnista epäterveelliset rutiinit korjaten ne terveellisiksi. (32.) En uskalla väittää, että paikallaanolon vähentäminen tai tauottaminen on helppoa, mutta uskallan väittää, että päiväkoti-ikäisen lapsen yksilölliset piirteet, koti ja päiväkoti kasvuympäristöinä ja perheen sosioekonominen asema muovaavat lapsen paikallaanoloa, ja nämä seikat tulisi huomioida paremmin tulevissa terveydenedistämisohjelmissa. Kannustankin kaikkia ottamaan enemmän askelia myös tänään.

\section{LÄHTEET}

1. Helsingin sanomat. Taukovoimistelu tapana jo monissa työpaikoissa. 10.lokakuutta 1963.

2. Lanningham-Foster L, Nysse LJ, Levine JA. Labor saved, calories lost: the energetic impact of domestic labor-saving devices. Obes Res 2003;11(10):1178-81.

Doi: https://doi.org/10.1038/oby.2003.162

3. Hill JO, Wyatt HR, Reed GW, ym. Obesity and the environment: where do we go from here? Science 2003; 299 (5608): 853-855. Doi: https://doi.org/10.1126/science.1079857

4. De Craemer M, Chastin S, Ahrens W ym. (2018). Data on determinants are needed to curb the sedentary epidemic in Europe. Lessons learnt from the DEDIPAC European knowledge hub. International Journal of Environmental Research and Public Health, 2018; 15(7).

Doi: https://doi.org/10.3390/ijerph15071406

5. Owen N, Sparling PB, Healy GN, ym. Sedentary behavior: emerging evidence for a new health risk. Mayo Clin Proc. 2010;85(12):1138-1141. Doi: https://doi.org/10.4065/mcp.2010.0444

6. Salmon J, Tremblay MS, Marshall SJ ym. Health risks, correlates, and interventions to reduce sedentary behavior in young people. Am J Prev Med, 2011; 41(2): 197-206.

Doi: https://doi.org/10.1016/j. amepre.2011.05.001

7. Zimmerman F, Christakis D, Meltzoff A. Television and DVD/video viewing in children younger than 2 years. Arch Pediatr Adolesc Med 2007;161:473-9

Doi: https://doi.org/10.1001/archpedi.161.5.473 
8. Pereira, JR, Cliff DP, Sousa-Sa E ym. Prevalence of objectively measured sedentary behavior in early years: Systematic review and meta-analysis. Scandinavian Journal of Medicine \& Science in Sports, 2019; 29(3):308-328

Doi: https://doi.org/10.1111/sms.13339

9. WHO. Report of the commission on ending childhood obesity. Geneve: WHO. 2016 Luettu 7.5.2020. http://www.who.int/endchildhood-obesity/publications/echo-report/en/. (9789241510066)

10. Tremblay MS, Aubert S, Barnes JD, ym. SBRN Terminology Consensus, P. P. (2017). Sedentary behavior research network (SBRN) - terminology consensus project process and outcome. The International Journal of Behavioral Nutrition and Physical Activity 2017; 14(1): 8. Doi: https://doi.org/10.1186/s12966-017-0525-8

11. Chen KY, Troiano, RP. (2017). Assessing sedentary behavior using motion sensors. Kirjassa W. Zhu, \& N. Owen (toim.), Sedentary behavior and health: Concepts, assessments, and interventions. Champaign, IL: Human Kinetics. 2015. Doi: https://doi.org/10.5040/9781492595861. ch-014

12. Tremblay MS, Carson V, Chaput JP, ym. Canadian 24-Hour Movement Guidelines for Children and Youth: An Integration of Physical Activity, Sedentary Behaviour, and Sleep. Appl Physiol Nutr Metab. 2016;41(6 Suppl 3):S311-S327.

Doi: https://doi.org/10.1139/apnm-2016-0203

13. Ekelund U, Steene-Johannessen J, Brown WJ, ym. Does physical activity attenuate, or even eliminate, the detrimental association of sitting time with mortality? A harmonised meta-analysis of data from more than 1 million men and women Lancet. 2016;388(10051):1302-1310. Doi: https://doi.org/10.1016/S01406736(16)30370-1

14. Chaput J, Olds T, Tremblay MS. Public health guidelines on sedentary behaviour are important and needed: a provisional benchmark is better than no benchmark at all. Br. J. Sports Med 2020;54:308-309.

Doi: https://doi.org/10.1136/ bjsports-2018-099964

15. Stamatakis E, Ekelund U, Ding D ym. Is the time right for quantitative public health guidelines on sitting? A narrative review of sedentary behaviour research paradigms and findings. Br J Sports Med 2019;53(6):377-382.

Doi: https://doi.org/10.1136/

bjsports-2018-099131

16. Vallance JK, Gardiner PA, Lynch BM, ym. Evaluating the Evidence on Sitting, Smoking, and Health: Is Sitting Really the New Smoking? Am J Public Health 2018;108(11):1478-1482. 304649 Doi: https://doi.org/10.2105/AJPH.2018.304649

17. Chau JY, Bonfiglioli C, Zhong A, ym. Sitting ducks face chronic disease: an analysis of newspaper coverage of sedentary behaviour as a health issue in Australia 2000-2012. Health Promot J Austr. 2017;28(2):139-143. Doi: https://doi.org/10.1071/HE16054
18. Owen N, Sugiyama T, Eakin EE ym.Adults' sedentary behavior determinants and interventions. Am J Prev Med 2011; 41(2): 189-196.

Doi: https://doi.org/10.1016/j. amepre.2011.05.013

19. Gardner B, Lally P, Wardle J. Making health habitual: the psychology of "habitformation" and general practice. Br J Gen Pract. 2012;62(605):664-666.

Doi: https://doi.org/10.3399/bjgp12X659466

20. OECD/European Observatory on Health Systems and Policies (2019), Suomi: Maan terveysprofiili 2019, State of Health in the EU, OECD Publishing, Paris/European Observatory on Health Systems and Policies, Brussels.

21. Gebremariam MK, Altenburg TM, Lakerveld J, Andersen LF, Stronks K, Chinapaw MJ, Lien N. Associations between socioeconomic position and correlates of sedentary behaviour among youth: A systematic review. Obesity Reviews 2015; 16(11): 988-1000.

Doi: https://doi.org/10.1111/obr.12314

22. Bronfenbrenner, U. The ecology of human development: Experiments by nature and design. Cambridge, MA: Harvard University press; 1979.

23. Hesketh KR \& van Sluijs EM.Features of the UK childcare environment and associations with preschooler's in-care physical activity. Prev Med Reports 2015; 3: 53-57. Doi: https://doi.org/10.1016/j.pmedr.2015.12.004

24. Määttä S, Ray C, Roos G ym. Applying a socioecological model to understand preschool Children's sedentary behaviors from the viewpoints of parents and preschool personnel. Early Childhood Education Journal, 2016; 44(5): 491-502. Doi: https://doi.org/10.1007/s10643-015-0737-y

25. Canadian Fitness and Lifestyle Research Institute Bulletin 04. (2010). Children's active pursuits during the after school period. Canadian Fitness \& Lifestyle research institute. Luettu 7.5.2020. http://www.cflri.ca/sites/default/files/node/922/ files /PAM\%202010\%20Bulletin \%204\%20-\%20 Active \%20Pursuits\%20EN.pdf

26. Hofferth S. "Changes in American children's time - 1997 to 2003," electronic International Journal of Time Use Research, Research Institute on Professions (Forschungsinstitut Freie Berufe (FFB)) and The International Association for Time Use Research (IATUR), 2009; 6 (1): 26-47. Doi: https://doi.org/10.13085/eIJTUR.6.1.26-47

27. Miettinen, Anneli \& Rotkirch, Anna. Yhteistä aikaa etsimässä. Lapsiperheiden ajankäyttö 2000-luvulla. Perhebarometri 2011. 2012. 135 s. Väestöliitto, Väestöntutkimuslaitos Katsauksia E 42 .

28. Hesketh KR, Lakshman R, van Sluijs, EMF. Barriers and facilitators to young children's physical activity and sedentary behaviour: A systematic review and synthesis of qualitative literature. Obesity Reviews, 2017; 1467-789. Doi: https://doi.org/10.1111/obr.12562 
29. Tremblay MS, Gray C, Babcock S. ym. Position statement on active outdoor play. International Journal of Environmental Research and Public Health 2015; 12(6): 6475-6505.

Doi: https://doi.org/10.3390/ijerph12060647

30. Dunstan D, Howard B, Healy G. ym. Too much sitting-A health hazard. Diabetes Res. Clin. Pract. 2012; 97: 368-376.

Doi: https://doi.org/10.1016/j. diabres.2012.05.020

31. Hidding LM,Altenburg TM, Van Ekris E. ym. Why Do Children Engage in Sedentary Behavior? Child- and Parent-Perceived Determinants. Int. J. Environ. Res. Public Health 2019;14: 671. Doi: https://doi.org/10.3390/ijerph14070671

32. Hidding LM, Altenburg TM, Van Ekris E, ym. Why Do Children Engage in Sedentary Behavior? Child- and Parent-Perceived Determinants. International Journal of Environmental Research and Public Health 2017; 14: 671.

Doi: https://doi.org/10.3390/ijerph14070671

33. García H, Miralles F, Cleary H. Ikigai: the Japanese secret to a long and happy life. New York: Penguin Books. 2017.

\section{Suvi MäÄтtä \\ VTT, LiTM \\ Tutkija \\ Helsingin yliopisto \\ Folkhälsanin tutkimuskeskus}

Valtiotieteiden maisteri, liikuntatieteiden maisteri Suvi Määtän väitöskirja "Preschool children's sedentary behavior: The role of individual characteristics, home and preschool settings, and socioeconomic status" tarkastettiin Helsingin yliopiston valtiotieteellisessä tiedekunnassa 09.06.2020. Vastaväittäjänä toimi dosentti Laura Ferrer Wreder Tukholman yliopistosta ja kustoksena professori Inga Jasinskaja-Lahti Helsingin yliopistosta. 